DOI 10. 18307/2018. 0203

(C) 2018 by Journal of Lake Sciences

\title{
富营养化湖泊沉积物有机质矿化过程中碳、氮、磷的迁移特征”
}

\author{
间兴成 ${ }^{1,2}$, 王明玥 ${ }^{1,2}$, 许晓光 ${ }^{1,2}$, 王国祥 ${ }^{1,2 * *}$, 孙 浩 ${ }^{1}$,杨云皓 ${ }^{1}$, 石 傲 ${ }^{1}$ \\ ( 1 : 南京师范大学环境学院, 南京 210023) \\ ( 2 : 江苏省地理信息资源开发与利用协同创新中心, 江苏省环境演变与生态建设重点实验室, 江苏省水土环境生态修复 \\ 工程实验室,南京 210023)
}

\begin{abstract}
摘 要: 采用室内培养的方法, 以富营养化湖泊太湖为例, 研究了沉积物有机质矿化过程中碳、氮、磷的迁移特征. 结果表 明, 在沉积物中的有机质矿化过程中, 碳以溶解性无机碳释放至水中, 同时以 $\mathrm{CH}_{4}$ 和 $\mathrm{CO}_{2}$ 形式释放至大气中, 培养结束时, $\mathrm{CH}_{4}$ 和 $\mathrm{CO}_{2}$ 累积排放含量分别为 1492.21 和 $498.96 \mathrm{mg} / \mathrm{g}\left(\mathrm{dw}\right.$ ), 其中 $\mathrm{CH}_{4}$ 占气态碳的 $89.16 \%$ ( 以 $\mathrm{C}$ 质量计) ; 此外, 大量的 氮、磷营养盐释放至上覆水体, 水中总氮、总磷和铵态氮的最高浓度分别是初始浓度的 $62.16 、 28.16$ 和 139.45 倍, 而硝态 氮浓度在整个培养过程中逐渐下降, 培养末期浓度是初期的 0.21 倍; 厌氧条件下, 沉积物有机质的矿化, 不仅可以生成大 量的 $\mathrm{CH}_{4} 、 \mathrm{CO}_{2}$ 气体, 还能够促使沉积物中铵态氮和磷的释放; 而沉积物有机质矿化释放的碳、氮、磷营养元素又能加剧湖 泊富营养化程度, 促进湖泊水体的初级生产力, 从而增加湖泊沉积物有机质输人. 这样的循环方式可能是湖泊富营养化 自维持的重要机制之一.
\end{abstract}

关键词: 沉积物; 有机质; 矿化; 碳; 氮; 磷; 迁移; 太湖

\section{Migration of carbon, nitrogen and phosphorus during organic matter mineralization in eu- trophic lake sediments}

YAN Xingcheng ${ }^{1,2}$, WANG Mingyue ${ }^{1,2}$, XU Xiaoguang ${ }^{1,2}$, WANG Guoxiang ${ }^{1,2 * *}$, SUN Hao ${ }^{1}$, YANG Yunhao $^{1} \&$ SHI Ao

(1: School of Environment, Nanjing Normal University, Nanjing 210023, P.R. China)

(2: Jiangsu Center for Collaborative Innovation in Geographical Information Resource Development and Application, Jiangsu Key Laboratory of Environmental Change and Ecological Construction, Jiangsu Engineering Laboratory of Water and Soil Eco-remediation, Nanjing 210023, P.R.China)

Abstract: The migration characteristics of carbon, nitrogen and phosphorus during organic matter mineralization were studied through laboratory incubation experiments, to simulate Lake Taihu, a large eutrophic lake in China. Results showed that sedimentary organic matter was mineralized and released dissolve inorganic carbon. At the end of incubation, the cumulative contents of $\mathrm{CH}_{4}$ and $\mathrm{CO}_{2}$ was $1492.21 \mathrm{mg} / \mathrm{g}(\mathrm{dw})$ and $498.96 \mathrm{mg} / \mathrm{g}(\mathrm{dw})$, respectively, with $\mathrm{CH}_{4}$ occupied $89.16 \%$ of gaseous carbon (in $\mathrm{C}$ mass). In addition, a large amount of nutrients, such as nitrogen and phosphorus, were released into overlying water. The highest concentrations of total nitogen, total phosphorus and ammonium nitrogen were $62.16,28.16$ and 139.45 times of the initial concentration, respectively. While nitrate nitrogen concentration declined throughout the incubation time, and its final concentration was 0.21 times of the initial concentration. Under anaerobic conditions, organic matter mineralization not only produced a large amount of $\mathrm{CH}_{4}, \mathrm{CO}_{2}$ but also promoted the release of ammonium nitrogen and phosphorus from sediments. These soluble inorganic nutrients further aggravate the lake eutrophication and promote the primary production, with subsequent increasing input of organic matter into lake sediment. This may be one of the important reasons for self-maintenance of lake eutrophication.

Keywords: Sediment; organic matter; mineralization; carbon; nitrogen; phosphorus ; migration; Lake Taihu

* 江苏省太湖水环境综合治理科研项目 (JSZC-G2014-212)、国家自然科学基金项目 (41573061) 和江苏省普通高校 研究生科研创新计划 (KYLX16 1295) 联合资助. 2017-05-08 收稿; 2017-07-02 收修改稿. 闰兴成( 1993 ), 男, 硕士研究生; E-mail: 15651658250@163.com.

** 通信作者; E-mail: wangguoxiang@ njnu.edu.cn. 
湖泊是地球表层系统中各个圈层相互作用的连接点,对区域乃至全球尺度上的碳等物质的循环具有重 要影响 ${ }^{[1]}$. 湖泊沉积物收纳了大量来自陆地生态系统的有机物质, 是全球重要的有机质储存场所 ${ }^{[2-4]}$. 碳作 为基本的生源要素之一, 其循环和代谢过程驱动着湖泊生态系统的基本过程, 是湖泊生态系统物质循环和 能量流动的主要载体 ${ }^{[5-6]}$. 湖泊通过内部的生态过程及其与流域的相互作用, 呈现极其活跃的碳源和碳汇等 功能, 碳循环过程不仅影响湖泊的生态过程和环境保护, 同时对全球变化具有重要影响 ${ }^{[1]}$. 关于湖泊沉积物 碳循环及其效应也逐渐成为研究热点.

过去几十年, 由于大尺度的土地利用类型的变化以及人类活动等对营养盐循环的改变,淡水湖泊水体 富营养化伴随着蓝藻水华暴发成为世界范围内环境管理的主要问题之一 ${ }^{[7]}$. 尽管湖泊面积占地球表面积的 比例很小, 但是其在全球范围的碳循环过程中扮演着重要的角色 ${ }^{[2]}$. 研究表明, 内陆淡水生态系统中沉积物 有机质的储存量与海洋和土壤相当 ${ }^{[8-11]}$, 甚至高于二者的有机质含量, 而且位于表层沉积物下方几厘米的沉 积物多为缺氧甚至厌氧环境 ${ }^{[12]}$. 有机质在戻氧条件下的降解不仅会产生 $\mathrm{CO}_{2}$, 而且还会产生大量的 $\mathrm{CH}_{4}$. Tranvik 等 ${ }^{[6]}$ 对全球湖泊 $\mathrm{CO}_{2}$ 排放量的估算表明, 总体上来看全球湖泊 $\mathrm{CO}_{2}$ 排放量高达 $0.53 \mathrm{Pg} \mathrm{C} / \mathrm{a}$, Bastviken 等 ${ }^{[13]}$ 通过对全球湖泊 $\mathrm{CH}_{4}$ 排放量的估算, 湖泊 $\mathrm{CH}_{4}$ 排放量相对 $\mathrm{CO}_{2}$ 来说较小, 为 $8 \sim 48 \mathrm{Tg} \mathrm{C} / \mathrm{a}$. 而 由于 $\mathrm{CH}_{4}$ 在水中的溶解度低, 以气泡形式释放的 $\mathrm{CH}_{4}$ 被认为是富营养化湖泊沉积物内源营养盐向上覆水迁 移的重要机制之一 ${ }^{[14-15]}$. 因此, 沉积物有机质的矿化, 不仅会产生 $\mathrm{CO}_{2}$ 和 $\mathrm{CH}_{4}$ 温室气体, 而且可能影响沉积物 内源营养盐的释放加剧湖泊富营养化.

湖泊近岸带以及水深较浅的区域在湖泊气体以及营养盐的收支中扮演着最为重要的角色 ${ }^{[14]}$. 太湖西 岸湖滨带是蓝藻聚集地, 湖面产生的蓝藻水华在风力作用在此聚集、堆积、腐烂、分解导致其周边水质恶化, 并且会降低水体的溶解氧浓度, 形成缺氧甚至厌氧的微环境 ${ }^{[16]}$. 课题组在以往的调查过程中发现, 太湖西 岸近岸湖滨带沉积物厚达 $1 \mathrm{~m}$ 左右, 呈黑色, 含有大量的植物残体, 有机质含量高, 而这类沉积物在厌氧条 件下, 有机质的矿化过程中的碳、氮、磷的迁移特征鲜见研究. 因此本实验选取太湖西岸符渎港附近湖滨带 表层沉积物为研究对象, 通过室内模拟实验, 阐明沉积物有机质在厌氧条件下的矿化过程中 $\mathrm{CO}_{2}$ 和 $\mathrm{CH}_{4}$ 气体 的排放量以及水中碳、氮、磷的动态特征, 旨在为深人研究湖泊近岸带沉积物有机质矿化过程及其对水环境 的影响提供参考.

\section{1 材料与方法}

采样点位在太湖竺山湾符渎港附近 $\left(31^{\circ} 14^{\prime} 45.61^{\prime \prime} \mathrm{N}, 120^{\circ} 0^{\prime} 45.01^{\prime \prime} \mathrm{E}\right)$, 于 2016 年 7 月, 用彼得森采泥器 采取表层 $(0 \sim 10 \mathrm{~cm})$ 沉积物, 并同时采集上覆水速运回实验室 $0 \sim 4^{\circ} \mathrm{C}$ 保存, 备用. 将采集的沉积物挑拣出大 颗粒杂质及植物残体后, 混匀, 待用; 水样经过 $0.45 \mu \mathrm{m}$ 滤网过滤后, 混匀, 待用. 初始水样中总氮 (TN)、总 磷 $(\mathrm{TP})$ 、铵态氮 $\left(\mathrm{NH}_{4}^{+}-\mathrm{N}\right)$ 、硝态氮 $\left(\mathrm{NO}_{3}^{-}-\mathrm{N}\right)$ 、无机氮 $(\mathrm{DIC})$ 浓度分别为 $2.31 、 0.32 、 0.38 、 1.45$ 和 $15.00 \mathrm{mg} / \mathrm{L}$, 沉积 物含水率为 $73.25 \%$, 烧失率为 $9.74 \%$.

实验在充分清洗干净的 $250 \mathrm{ml}$ 的培养瓶中进行, 向其中加人 $100 \mathrm{~g}$ 沉积物 (湿重), 加人 $100 \mathrm{ml}$ 过滤及 混匀后的水样, 用高纯 $\mathrm{N}_{2}$ 赶走内部空气, 随即盖上盖子密封, 在 $28 \pm 0.5^{\circ} \mathrm{C}$ 条件下培养, 此时, 培养瓶上部空间 体积为 $108 \mathrm{ml}$. 分别于培养的第 $0 、 2 、 5 、 9 、 20 、 30 、 38 、 44 、 47 、 51$ 和 $60 \mathrm{~d}$ 采样, 每个样品设置 3 个平行.

采样时, 用注射器抽取内部气体, 注人已抽真空的气体样品瓶中, 待分析. 虹吸法取出培养瓶内水样, 测 定水样中 $\mathrm{TN} 、 \mathrm{TP} 、 \mathrm{NH}_{4}^{+}-\mathrm{N} 、 \mathrm{NO}_{3}^{-}-\mathrm{N}$ 和 DIC 浓度. $\mathrm{TN}$ 、 $\mathrm{TP}$ 浓度采用碱性过硫酸钾联合消解法测定 ${ }^{[17-18]} ; \mathrm{NH}_{4}^{+}-\mathrm{N}$ 、 $\mathrm{NO}_{3}^{-}-\mathrm{N}$ 浓度用连续流动分析仪 (Auto Analyzer 3, 德国) 测定, DIC 浓度用 $\mathrm{C} / \mathrm{N}$ 分析仪 (HT 1300, Analytic Jena, 德国) 测定, $\mathrm{CO}_{2}$ 和 $\mathrm{CH}_{4}$ 含量用气相色谱仪 (Aglient, 7890B $)^{[19]}$ 测定. 含水率测定时, 称取混匀后的沉积 物, 于 $105^{\circ} \mathrm{C}$ 条件下烘干至恒重, 含水率由烘干前后的质量损失计算. 将烘干后的样品放人马弗炉中, 于 $550^{\circ} \mathrm{C}$ 条件下处理 $5 \mathrm{~h}$, 处理前后的质量差即为烧失率. $\mathrm{CO}_{2}$ 和 $\mathrm{CH}_{4}$ 气体含量单位为 $\mathrm{mg} / \mathrm{g}(\mathrm{dw})$, 表示单位干重 沉积物所产生的气体的量,由含水率换算得到.

数据作图及分析分别采用 Origin 8.0 和 SPSS 18.0 软件. 


\section{2 结果与分析}

\section{1 水体碳、氮、磷浓度的动态变化}

随着沉积物有机质的矿化,水中 $\mathrm{TN} 、 \mathrm{TP} 、 \mathrm{NH}_{4}^{+}-\mathrm{N}$ 和 DIC 浓度显著升高, 而 $\mathrm{NO}_{3}^{-}-\mathrm{N}$ 浓度逐渐降低(图 1). 其中水中 $\mathrm{TN}$ 浓度在 $0 \sim 9 \mathrm{~d}$ 上升速率最快, 由 $32.76 \mathrm{mg} / \mathrm{L}$ 迅速上升至 $95.03 \mathrm{mg} / \mathrm{L}, 38 \mathrm{~d}$ 以后, 水中 $\mathrm{TN}$ 浓度 基本平稳, 最高浓度达到 $143.59 \mathrm{mg} / \mathrm{L}$ (图 1a). 水中 $\mathrm{NH}_{4}^{+}-\mathrm{N}$ 浓度在培养初期的 $2 \mathrm{~d}$ 内, 浓度由 $27.50 \mathrm{mg} / \mathrm{L}$ 上 升至 $40.87 \mathrm{mg} / \mathrm{L}$, 在培养的第 $38 \mathrm{~d}$ 浓度达到峰值, 为 $52.99 \mathrm{mg} / \mathrm{L}$, 之后略有下降 (图 1c). 而水中 $\mathrm{NO}_{3}^{-}-\mathrm{N}$ 浓度 在整个培养期间逐渐下降, 且在 $0 \sim 9 \mathrm{~d}$ 内下降速率最快, 由 $1.17 \mathrm{mg} / \mathrm{L}$ 下降至 $0.77 \mathrm{mg} / \mathrm{L}$, 培养结束时, 水中 $\mathrm{NO}_{3}^{-}-\mathrm{N}$ 浓度为 $0.31 \mathrm{mg} / \mathrm{L}$ (图 $1 \mathrm{~d}$ ). 水中 $\mathrm{TP}$ 浓度由 $1.37 \mathrm{mg} / \mathrm{L}($ 第 $9 \mathrm{~d}$ ) 迅速上升至 $8.47 \mathrm{mg} / \mathrm{L}($ 第 $20 \mathrm{~d}$ ), 上升 了 6 倍, 之后 TP 浓度基本平稳, 最高值为 $9.01 \mathrm{mg} / \mathrm{L}$ (第 $60 \mathrm{~d}$ ) (图 1b). 沉积物有机质矿化过程中, 除了会释 放大量的 N、P 营养盐外, 还会向水体释放大量的 DIC. 在整个培养期间, 水中 DIC 浓度逐渐上升, 于第 $47 \mathrm{~d}$ 浓度达到最高, 为 $345.70 \mathrm{mg} / \mathrm{L}$, 之后浓度基本平稳 (图 1e). 培养过程中, 水中 $\mathrm{TN} 、 \mathrm{TP} 、 \mathrm{NH}_{4}^{+}-\mathrm{N}$ 和 DIC 的最高 浓度分别为初始浓度的 $62.16 、 28.16 、 139.45$ 和 23.05 倍, 而水中 $\mathrm{NO}_{3}^{-}-\mathrm{N}$ 浓度在培养末期是初始浓度的 0.21 倍.
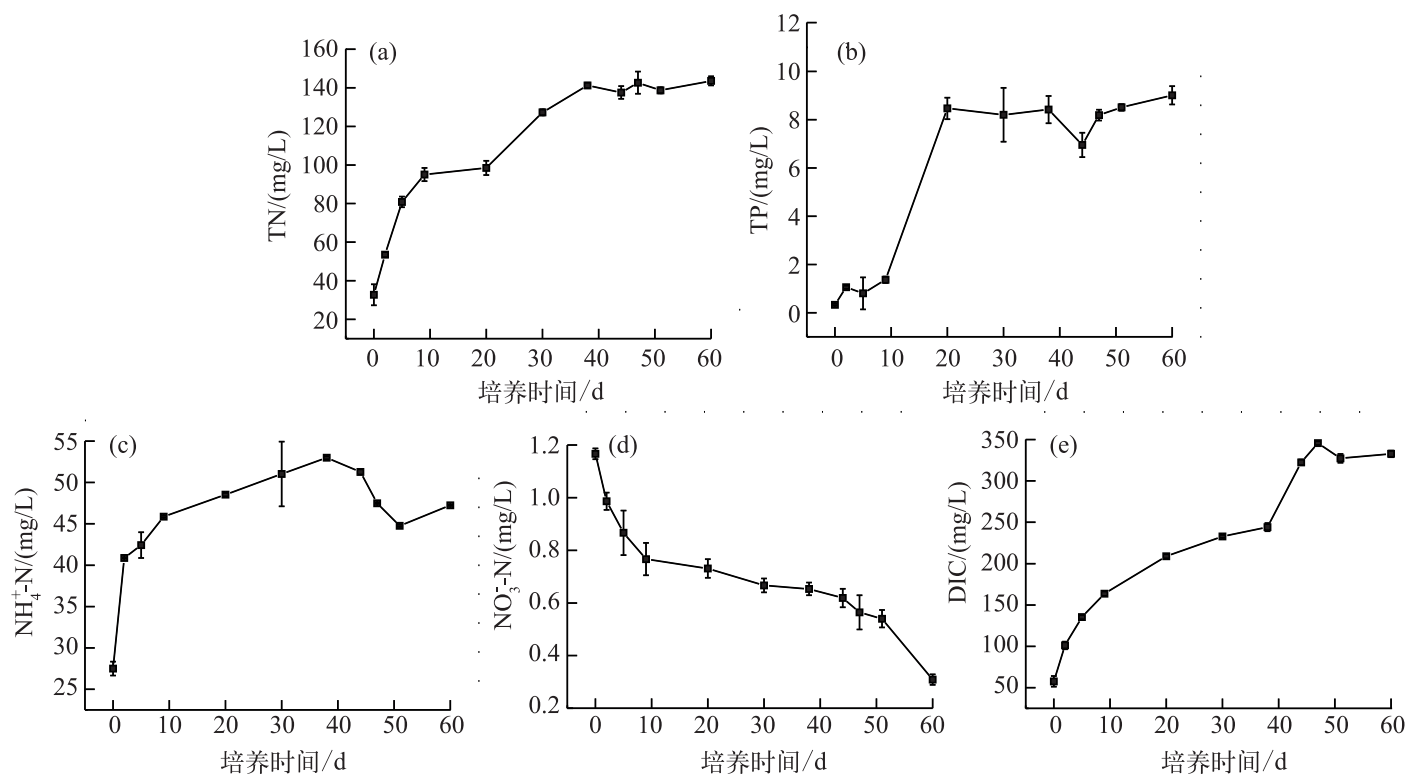

图 1 水中溶解性无机碳、氮、磷浓度动态变化

Fig. 1 The dynamics of dissolved inorganic carbon, nitrogen and phosphorus concentration in the overlying water

\section{$2.2 \mathrm{CO}_{2}$ 和 $\mathrm{CH}_{4}$ 含量的动态特征}

沉积物有机质在相对厌氧的条件下,会被厌氧微生物利用、发酵,除了产生 $\mathrm{CO}_{2}$ 外,还会以 $\mathrm{CH}_{4}$ 形式向外 界释放. 本研究表明,在沉积物培养期间, 气体中 $\mathrm{CH}_{4}$ 含量逐渐上升,其中第 $9 \sim 20 \mathrm{~d}$ 上升速度最快, 由 39.55 $\mathrm{mg} / \mathrm{g}(\mathrm{dw})$ 上升至 $845.72 \mathrm{mg} / \mathrm{g}(\mathrm{dw})$. 第 $20 \mathrm{~d}$ 之后, $\mathrm{CH}_{4}$ 含量上升速率逐渐降低, 培养结束时, $\mathrm{CH}_{4}$ 的累积排放 含量为 $369.60 \mathrm{mg} / \mathrm{g}\left(\mathrm{dw}\right.$ ) (图 2a). $\mathrm{CO}_{2}$ 含量在培养初期 (第 2 9 d) 上升速率最快, 第 $9 \mathrm{~d}$ 之后 $\mathrm{CO}_{2}$ 含量上升 速率逐渐变缓,第 $30 \mathrm{~d}$ 以后, $\mathrm{CO}_{2}$ 含量基本保持稳定. 培养结束时, $\mathrm{CO}_{2}$ 含量为 $498.96 \mathrm{mg} / \mathrm{g}(\mathrm{dw})$ (图 2b). 沉 积物有机质矿化过程中, 碳以 $\mathrm{CO}_{2}$ 和 $\mathrm{CH}_{4}$ 的形式向外界迁移, 本实验中, 碳主要以 $\mathrm{CH}_{4}$ 的形式向大气释放. 在 整个培养期间, $\mathrm{CH}_{4}$ 最高含量是 $\mathrm{CO}_{2}$ 最高含量的 8 倍 ( 以 $\mathrm{C}$ 质量计).

\section{3 培养期间沉积物烧失率的变化}

用烧失率来反映沉积物中有机质含量的动态变化, 其值越高, 表示沉积物有机质含量越高, 反之, 越低. 

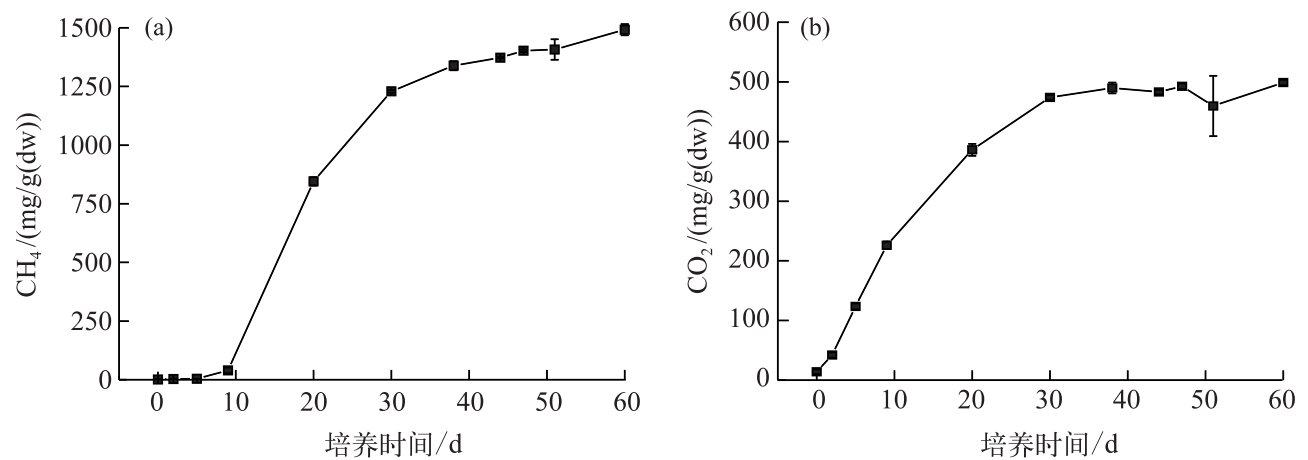

图 2 甲烷、二氧化碳含量动态变化

Fig.2 The dynamics of methane and carbon dioxide contents in the overlying water

在整个培养期间, 沉积物烧失率逐渐下降,由最高的 $9.97 \%$ 下降至培养结束时的 $8.02 \%$, 表明沉积物有机 质在培养期间部分矿化,其含量逐渐降低 (图 3). 由 于沉积物组分复杂, 尽管已经挑选出其中的颗粒物和 植物残体, 但是也很难保证绝对的一致. 从整体上来 看, 沉积物烧失率呈下降趋势.

\section{4 水体碳、氮、磷浓度与 $\mathrm{CO}_{2}$ 和 $\mathrm{CH}_{4}$ 含量的相互关系}

本研究表明,沉积物有机质的矿化, 除了会使碳 向上覆水和大气中释放, 还会释放氮、磷营养盐. 为 了进一步了解水体有机质矿化过程中各指标之间的 相互关系,本研究对各指标进行相关性分析. 结果表 明,除 $\mathrm{NH}_{4}^{+}-\mathrm{N}$ 浓度和烧失率外, 其他各指标之间相关 性显著 (表 1). $\mathrm{TN}$ 浓度与 $\mathrm{CO}_{2}$ 含量相关性最为显著 $(P<0.01), \mathrm{TP}$ 浓度与 $\mathrm{CH}_{4}$ 含量相关性最为显著 $(P<$ $0.01), \mathrm{NO}_{3}^{-}-\mathrm{N}$ 浓度和烧失率与所有指标均呈显著负

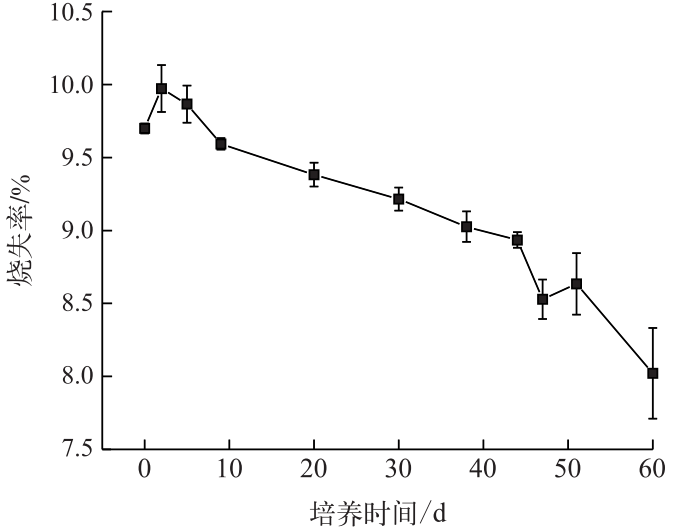

图 3 培养期间沉积物烧失率的变化 Fig.3 The loss in ignition of sediment dynamics during the incubation time 相关 $(P<0.01)$, 沉积物烧失率与水中 DIC 浓度显著负相关水平最高 $(P<0.01), \mathrm{CH}_{4}$ 与 $\mathrm{CO}_{2}$ 含量相关性最为 显著 $(P<0.01)$.

表 1 水体碳、氮、磷浓度与 $\mathrm{CO}_{2}$ 和 $\mathrm{CH}_{4}$ 含量的相互关系

Tab.1 Relationship between $\mathrm{CO}_{2}, \mathrm{CH}_{4}$ contents and carbon, nitrogen, phosphorus concentrations in the overlying water

\begin{tabular}{ccccccccc}
\hline & $\mathrm{TN}$ & $\mathrm{TP}$ & $\mathrm{NH}_{4}^{+}-\mathrm{N}$ & $\mathrm{NO}_{3}^{-}-\mathrm{N}$ & $\mathrm{DIC}$ & 烧失率 & $\mathrm{CH}_{4}$ & $\mathrm{CO}_{2}$ \\
\hline $\mathrm{TN}$ & 1 & & & & & & & \\
$\mathrm{TP}$ & $0.874^{* *}$ & 1 & & & & & & \\
$\mathrm{NH}_{4}^{+}-\mathrm{N}$ & $0.833^{* *}$ & $0.722^{*}$ & 1 & & & & \\
$\mathrm{NO}_{3}^{-}-\mathrm{N}$ & $-0.932^{* *}$ & $-0.834^{* *}$ & $-0.736^{* *}$ & 1 & & & & \\
$\mathrm{DIC}$ & $0.948^{* *}$ & $0.863^{* *}$ & $0.691^{*}$ & $-0.929^{* *}$ & 1 & & & \\
烧失率 & $-0.837^{* *}$ & $-0.863^{* *}$ & $-0.459^{* *}$ & $0.902^{* *}$ & $-0.910^{* *}$ & 1 & & \\
$\mathrm{CH}_{4}$ & $0.920^{* *}$ & $0.958^{* *}$ & $0.682^{*}$ & $-0.855^{* *}$ & $0.929^{* *}$ & $-0.835^{* *}$ & 1 \\
$\mathrm{CO}_{2}$ & $0.968^{* *}$ & $0.952^{* *}$ & $0.818^{* *}$ & $-0.896^{* *}$ & $0.928^{* *}$ & $-0.887^{* *}$ & $0.960^{* *}$ & 1 \\
\hline
\end{tabular}

* 表示在 $P<0.05$ 水平上相关性显著; $* *$ 表示在 $P<0.01$ 水平上相关性显著, $n=33$. 


\section{3 讨论}

富营养化浅水湖泊蓝藻水华暴发会造成区域缺氧甚至厌氧, 一是由于蓝藻水华的遮蔽作用阻碍大气复 氧, 极易使水一沉积物界面形成缺氧的分解环境; 二是蓝藻水华暴发后在水面聚集、堆积、衰亡使得水中的 溶解氧消耗殆尽, 造成水体缺氧、戻氧 ${ }^{[20-22]}$. 内陆湖泊水体沉积物有机质来源广泛且复杂,包括来自自身生 产力的有机质和陆源输人的有机质, 而湖泊水体沉积物不仅可以储存有机质, 同时也是大量有机质矿化最 为活跃的场所 ${ }^{[2,6]}$. 沉降到沉积物中的有机质部分在异养微生物的作用下被矿化, 生成 $\mathrm{CO}_{2}$ 和 $\mathrm{CH}_{4}$, 部分则 被保存在沉积物中 ${ }^{[6]}$. 沉积物有机质的矿化速率与温度、氧气含量等因素有关 ${ }^{[6,23-24]}$.

本研究选择太湖西岸湖滨带表层沉积物为研究对象, 重点关注这类沉积物在厌氧条件下的矿化过程 中, 碳、氮、磷的迁移特征. 结果表明, 太湖西岸湖滨带表层沉积物在厌氧条件下的矿化过程中, 会向上覆水 中释放大量的无机碳 (图 1e). 相比于氮、磷, 淡水生态系统中无机碳的可利用性更高 ${ }^{[25]}$. 近几十年以来, 人类 活动导致大量的氮、磷等营养盐输人至湖泊水体中, 当水中 $\mathrm{C}: \mathrm{N}: \mathrm{P}$ 值低于一定比例时 $(\mathrm{C}: \mathrm{N}: \mathrm{P}=106: 16: 1)$, 系 统中初级生产者对碳的需求超过了对氮、磷等营养盐的需求 ${ }^{[26]}$, 碳可能成为水生系统中主要的非生物限制 因子 ${ }^{[27]}$. 因此,湖泊近岸带沉积物中有机质的矿化过程可能会在一定程度上弥补这一现象.

本研究中, 湖泊沉积物有机质矿化过程中, 除了会向上覆水释放无机碳, 还能以气体形式释放大量的 $\mathrm{CO}_{2}$ 和 $\mathrm{CH}_{4}$. 研究表明, 浅水湖泊水一沉积物界面被认为是有机质的汇集场所, 其呼吸作用占湖泊总呼吸量的 $50 \%$ 以上 ${ }^{[28]}$, 而每年沉积物中的有机质有 7\% 75\%会被矿化形成 $\mathrm{CO}_{2}$ 和 $\mathrm{CH}_{4}^{[29-30]}$. 从烧失率来看, 在整个培 养过程中, 沉积物烧失率逐渐降低, 反映出沉积物中的有机质在厌氧条件下可以逐渐分解产生无机组分, 如 产生无机形态的碳、氮和磷. 有机质厌氧矿化产 $\mathrm{CH}_{4}$ 过程根据其产生途径可以分为 2 种类型, 一是通过利用 乙酸生成 $\mathrm{CH}_{4}$ 和 $\mathrm{CO}_{2}$ 的食乙酸产甲烷菌, 如 Methanosaeta; 二是通过利用 $\mathrm{H}_{2}$ 和 $\mathrm{CO}_{2}$ 合成 $\mathrm{CH}_{4}$ 的食氢产甲烷菌, 如 Methanomicrobiales 和 Methanobacteriaceae ${ }^{[31]}$. 本研究中,气态形式的碳主要以 $\mathrm{CH}_{4}$ 形式向外迁移, 占向外 迁移碳的 $89.33 \%$ ( 以 C 质量计). 而已有的研究中, $\mathrm{CH}_{4}$ 的排放量占比在 $20 \% \sim 42 \%$ 之间 ${ }^{[30,32]}$, 如 Liikanen 等 ${ }^{[24]}$ 的研究表明, 在厌氧条件下, 有机质矿化过程中 $\mathrm{CH}_{4}$ 的排放量占 $\mathrm{CO}_{2}$ 和 $\mathrm{CH}_{4}$ 之和的 $34 \%$,均低于本研究 的结果. 一个可能的原因是在本实验中, $\mathrm{CH}_{4}$ 更多的是由 $\mathrm{CO}_{2}$ 和 $\mathrm{H}_{2}$ 产生的, 而不是醋酸发䤉产生的, 因此在 $\mathrm{CH}_{4}$ 的生成过程中会消耗部分的 $\mathrm{CO}_{2}^{[33-34]}$. 由于本实验中, 未对产 $\mathrm{CH}_{4}$ 微生物进行分析研究, 因此, 对于富营 养化湖泊近岸带沉积物有机质矿化产 $\mathrm{CH}_{4}$ 的微生物过程有待进一步研究.

富营养化湖泊近岸带表层沉积物的有机质矿化过程中, 除了会引起碳的迁移转化, 还会影响沉积物内 源氮、磷等营养盐向上覆水中释放. 本研究中, 由于在相对缺氧条件下, $\mathrm{NO}_{3}^{-}-\mathrm{N}$ 会通过反硝化作用生成 $\mathrm{N}_{2} \mathrm{O}$ 和 $\mathrm{N}_{2}^{[24]}$, 因此上覆水中 $\mathrm{NO}_{3}^{-}-\mathrm{N}$ 浓度逐渐降低. 同时, 有机质矿化过程中产生 $\mathrm{NH}_{4}^{+}-\mathrm{N}$ 由于缺氧不能通过硝化 作用转化为 $\mathrm{NO}_{3}^{-}-\mathrm{N}$, 因此在整个培养过程中, $\mathrm{NH}_{4}^{+}-\mathrm{N}$ 浓度逐渐增加. 沉积物有机质矿化过程中, 会引起磷向 上覆水中释放. 一方面来源于有机质分解过程; 另一方面, 富营养化湖泊沉积物本身作为磷储存的重要场 所, 是上覆水磷的重要来源之一 ${ }^{[35]}$. 沉积物中的磷可以和铁氧化物结合, 在缺氧或者厌氧条件下, 沉积物中 的 $\mathrm{Fe}$ ( III ) 还原成 $\mathrm{Fe}$ ( II ), 使得与之结合的磷释放 ${ }^{[34]}$.

本实验中, 氮、磷的释放与 $\mathrm{CO}_{2} 、 \mathrm{CH}_{4}$ 生成相关性显著, 其中 $\mathrm{TN}$ 浓度与 $\mathrm{CO}_{2}$ 含量相关性最为显著, $\mathrm{TP}$ 浓 度与 $\mathrm{CH}_{4}$ 含量相关性最为显著, 表明沉积物氮、磷的释放与微生物活动密切相关 ${ }^{[36-37]}$. Schultz 等 ${ }^{[38]}$ 从微生 物学角度对沉积物有机质分解及营养盐的释放进行建模研究, 结果也证明, 沉积物营养盐的释放与有机质 的供给速率和来源有关, 细菌对有机质矿化速率与基质的质量有关. 沉积物有机质矿化引起的营养元素的 释放, 会在一定程度上加剧湖泊的富营养化, 而湖泊沉积物疏浚是被广泛应用的内源污染控制技术, 对内源 氮、磷负荷的削减具有显著效果 ${ }^{[39-40]}$. 结合本研究结果来看, 富营养化湖泊沉积物疏浚不仅能有效控制内源 氮、磷的负荷, 而且还能够减少湖泊近岸带 $\mathrm{CO}_{2}$ 和 $\mathrm{CH}_{4}$ 温室气体的排放.

综上, 富营养化湖泊近岸带沉积物有机质的矿化, 会产生 $\mathrm{CO}_{2}$ 和 $\mathrm{CH}_{4}$ 温室气体. 由于 $\mathrm{CH}_{4}$ 在水中的溶解 度低, 因此大量的 $\mathrm{CH}_{4}$ 主要以分子扩散和冒泡的形式释放到大气中, 其中以冒泡形式释放被认为是主要途 径 ${ }^{[13,41]}$, 这种方式又会扰动沉积物, 从而也被认为是沉积物营养盐向上覆水迁移的重要机制之一 ${ }^{[14-15]}$. 沉积 物有机质的矿化不仅释放 $\mathrm{CO}_{2}$ 和 $\mathrm{CH}_{4}$ 温室气体, 还能够使得沉积物中的碳、氮、磷等营养元素释放至水体中, 
释放至水体中的营养盐又能够促进初级生产力, 增加沉积物有机质来源, 这种循环方式也是湖泊长期保持 富营养化状态的主要机制.

\section{4 结论}

1) 富营养化湖泊近岸带沉积物有机质矿化过程中,碳一部分以无机碳的形式释放至上覆水体,一部分 以 $\mathrm{CO}_{2}$ 和 $\mathrm{CH}_{4}$ 形式释放到大气中, 其中 $\mathrm{CH}_{4}$ 是碳以气态向大气释放的主要形式, 但富营养化湖泊近岸带沉积 物有机质矿化产甲烷的微生物过程有待进一步研究.

2) 富营养化湖泊近岸带沉积物有机质矿化会释放大量营养盐,造成上覆水 TN、TP、 $\mathrm{NH}_{4}^{+}-\mathrm{N}$ 浓度显著上 升, 释放的营养盐对湖泊富营养化有一定贡献, 促进湖泊初级生产力, 从而增加湖泊沉积物有机质输人. 如 此循环, 可能是维持湖泊长期富营养化机制之一.

3) 富营养化湖泊近岸带沉积物疏浚不仅能够削减沉积物内源氮、磷等的负荷,而且还能有助于减少湖 泊近岸带 $\mathrm{CO}_{2}$ 和 $\mathrm{CH}_{4}$ 温室气体的排放.

\section{5 参考文献}

[ 1 ] Wu QL, Xing P, Li HB et al. Impacts of regime shift between phytoplankton and macrophyte on the microbial community structure and its carbon cycling in lakes. Microbiology China, 2013, 40 (1) : 87-97. DOI: 10.13344/j. microbiol.china. 2013.01.003. [吴庆龙, 邢鹏, 李化炳等. 草藻型稳态转换对湖泊微生物结构及其碳循环功能的影响. 微生物学通 报, 2013, 40(1): 87-97.]

[ 2 ] Cole JJ, Prairie YT, Caraco NF et al. Plumbing the global carbon cycle: integrating inland waters into the terrestrial carbon budget. Ecosystems, 2007, 10(1) : 172-185. DOI: 10.1007/s10021-006-9013-8.

[ 3 ] Cole JJ, Caraco NF, Kling GW et al. Carbon dioxide super saturation in the surface waters of lakes. Science, 1994,265 (5178) : 1568-1570.

[ 4 ] Marotta H, Duarte CM, Sobek S et al. Large $\mathrm{CO}_{2}$ disequilibria in tropical lakes. Global Biogeochemical Cycles, 2009, 23 (4) : GB4022. DOI: 10.1029/2008GB003434.

[ 5 ] Lembi CA. Limnology, lake and river ecosystems. Journal of Phycology, 2001, 37 (6) : 1146-1147. DOI: 10.1046/j. 1529-8817.2001.37602.x.

[ 6 ] Tranvik LJ, Downing JA, Cotner JB et al. Lakes and reservoirs as regulators of carbon cycling and climate. Limnology and Oceanography, 2009, 54(6part2) : 2298-2314. DOI: 10.4319/lo.2009.54.6_part_2.2298.

[ 7 ] Moe SJ, Haande S, Couture RM. Climate change, cyanobacteria blooms and ecological status of lakes: A Bayesian network approach. Ecological Modelling, 2016, 337: 330-347. DOI: org/10.1016/j.ecolmodel.2016.07.004.

[ 8 ] Einsele G, Yan J, Hinderer M. Atmospheric carbon burial in modern lake basins and its significance for the global carbon budget. Global \& Planetary Change, 2001, 30(3) : 167-195. DOI: 10.1016/S0921-8181( 01) 00105-9.

[ 9 ] Downing JA, Cole JJ, Middelburg JJ et al. Sediment organic carbon burial in agriculturally eutrophic impoundments over the last century. Global Biogeochemical Cycles, 2008, 22(1): GB1018. DOI: 10.1029/2006GB002854.

[10] Schlesinger WH. Evidence from chronosequence studies for a low carbon-storage potential of soils. Nature, 1990,348 (6298) : 232-234. DOI: 10.1038/348232a0.

[11] Rapalee G, Trumbore SE, Davidson EA et al. Soil carbon stocks and their rates of accumulation and loss in a boreal forest landscape. Global Biogeochemical Cycles, 1998, 12(4) : 687-702. DOI: 10.1029/98GB02336.

[12] Sobek S, Durisch-Kaiser E, Zurbrügg R et al. Organic carbon burial efficiency in lake sediments controlled by oxygen exposure time and sediment source. Limnology and Oceanography, 2009, 54(6) : 2243-2254. DOI : 10.4319/lo.2009.54. 6.2243 .

[13] Bastviken D, Cole J, Pace M et al. Methane emissions from lakes: Dependence of lake characteristics, two regional assessments, and a global estimate. Global Biogeochemical Cycles, 2004, 18: GB4009. DOI: 10.1029/2004GB002238.

[14] Liikanen A, Huttunen JT, Murtoniemi T et al. Spatial and seasonal variation in greenhouse gas and nutrient dynamics and their interactions in the sediments of a boreal eutrophic lake. Biogeochemistry, 2003, 65 (1) : 83-103. DOI: 10.1023/ A: 1026070209387.

[15] Varjo E, Liikanen A, Salonen VP et al. A new gypsum-based technique to reduce methane and phophorus release from 
sediments of eutrophied lakes: Gypsum treatment to reduce internal loading. Water Research, 2003, 37 ( 1) : 1-10. DOI: 10.1016/s0043-1354( 02) 00264-6.

[16] Wang H, Lu J, Wang W et al. Methane fluxes from the littoral zone of hypereutrophic Taihu Lake, China. Journal of Geophysical Research-Atmospheres, 2006, 111(D17) : 4093-4100. DOI: 10.1029/2005JD006864.

[17] Raveh A, Avnimelech Y. Total nitrogen analysis in water, soil and plant material with persulphate oxidation. Water Research, 1979, 13(9) : 911-912. DOI: org/10.1016/0043-1354(79)90227-6.

[18] Ebina J, Tsutsui T, Shirai T. Simultaneous determination of total nitrogen and total phosphorus in water using peroxodisulfate oxidation. Water Research, 1983, 17(12) : 1721-1726. DOI: org/10.1016/0043-1354(83)90192-6.

[19] Bastviken D, Santoro AL, Marotta H et al. Methane emissions from Pantanal, South America, during the low water season: Toward more comprehensive sampling. Environmental Science \& Technology, 2010, 44(14) : 5450-5455. DOI: 10. $1021 /$ es1005048.

[20] Xing P, Guo L, Tian W et al. Novel Clostridium populations involved in the anaerobic degradation of Microcystis blooms. Isme Journal, 2011, 5(5) : 792-800. DOI: 10.2307/2259418.

[21] Li H, Xing P, Chen M. Short-term bacterial community composition dynamics in response to accumulation and breakdown of Microcystis blooms. Water Research, 2011, 45(4) : 1702. DOI: 10.1016/j.watres.2010.11.011.

[22] Li H, Xing P, Wu QL. Characterization of the bacterial community composition in a hypoxic zone induced by Microcystis blooms in Lake Taihu, China. FEMS Microbiology Ecology, 2012, 79(3) : 773-784. DOI: 10.1111/j.1574-6941.2011. 01262.x.

[23] Gudasz C. Temperature-controlled organic carbon mineralization in lake sediments. Nature, 2010, 466(7305) : 478. DOI: 10.1038/nature09186.

[24] Liikanen A, Murtoniemi T, Tanskanen $\mathrm{H}$ et al. Effects of temperature and oxygen availability on greenhouse gas and nutrient dynamics in sediment of a eutrophic mid-boreal lake. Biogeochemistry, 2002, 59( 3 ) : 269-286. DOI: 10.1023/ A: 1016015526712 .

[25] Smil V. Phosphorus in the environment: Natural Flows and Human Interferences. Annual Review of Energy \& the Environment, 2003, 25(1) : 53-88. DOI: 10.1146/annurev.energy.25.1.53.

[26] Li W, Xu X, Fujibayashi M et al. Response of microalgae to elevated $\mathrm{CO}_{2}$ and temperature: impact of climate change on freshwater ecosystems. Environmental Science \& Pollution Research, 2016, 23 (19): 19847-19860. DOI: 10.1007/ s11356-016-7180-5.

[27] Lowdécarie E, Bell G, Fussmann GF. $\mathrm{CO}_{2}$ alters community composition and response to nutrient enrichment of freshwater phytoplankton. Oecologia , 2015, 177(3) : 875-883. DOI : 10.1007/s00442-014-3153-x.

[28] Richey JE, Wissmar RC, Devol AH et al. Carbon flow in four lake ecosystems: A structural approach. Science, 1978,202 (4373) : 1183. DOI: 10.1126/science.202.4373.1183.

[29] Jones JG, Simon BM. Decomposition processes in the profundal region of Blelham Tarn and the Lund Tubes. Journal of Ecology, 1980, 68(2) : 493-512. DOI: 10.2307/2259418.

[30] Kelley CA, Martens CS, Chanton JP. Variations in sedimentary carbon remineralization rates in the White Oak River estuary, North Carolina. Limnology \& Oceanography, 1990, 35(2) : 372-383. DOI: 10.2307/2259418.

[31] Høj L, Olsen RA, Torsvik VL. Effects of temperature on the diversity and community structure of known methanogenic groups and other archaea in high arctic peat. Isme Journal, 2008, 2(1) : 37-48. DOI: 10.1038/ismej.2007.84.

[32] den Heyer C, Kalff J. Organic matter mineralization rates in sediments: A within-and among-lake study. Limnology and Oceanography, 1998, 43(4) : 695-705. DOI: 10.4319/lo.1998.43.4.0695.

[33] Conrad R, Noll M, Claus P et al. Stable carbon isotope discrimination and microbiology of methane formation in tropical anoxic lake sediments. Biogeosciences, 2010, 8(3) : 23459-23473. DOI: 10.5194/bgd-7-8619-2010.

[34] Schulz S, Conrad R. Influence of temperature on pathways to methane production in the permanently cold profundal sediment of Lake Constance. FEMS Microbiology Ecology, 1996, 20(1) : 1-14. DOI: 10.1016/0168-6496(96) 00009-8.

[35] Jiang X, Jin X, Yao Y et al. Effects of oxygen on the release and distribution of phosphorus in the sediments under the light condition. Environmental Pollution, 2006, 141(3) : 482-487. DOI: 10.1016/j.envpol.2005.08.071.

[36] Holdren GC, Armstrong DE. Factors affecting phosphorus release from intact lake sediment cores. Environmental Science \& Technology, 1980, 14(1) : 79-87. DOI: 10.1021/es60161a014. 
[37] Søndergaard M, Jeppesen E, Kristensen P et al. Interactions between sediment and water in a shallow and hypertrophic lake: A study on phytoplankton collapses in Lake Søbygård, Denmark. Hydrobiologia, 1990, 191(1) : 139-148. DOI: 10. 1007/978-94-009-0467-5_17.

[38] Schultz P, Urban NR. Effects of bacterial dynamics on organic matter decomposition and nutrient release from sediments: A modeling study. Ecological Modelling, 2008, 210(1/2) : 1-14. DOI: org/10.1016/j.ecolmodel.2007.06.026.

[39] Zhong JC, Liu GF, Fan CX et al. Environmental effect of sediment dredging in lake( I) : the role of sediment dredging in reducing internal phosphorus release. J Lake Sci, 2009, 21(1): 84-93. DOI:10.18307/2009.0111. [钟继承, 刘国锋, 范成新等. 湖泊底泥疏浚环境效应: I .内源磷释放控制作用. 湖泊科学, 2009, 21(1): 84-93.]

[40] Zhong JC, Liu GF, Fan CX et al. Environmental effect of sediment dredging in lake( II ): the role of sediment dredging in reducing internal nitrogen release. J Lake Sci, 2009, 21(3): 335-344. DOI: 10.18307/2009.0304. [ 钟继承, 刘国锋, 范成新等. 湖泊底泥疏浚环境效应：II.内源氮释放控制作用. 湖泊科学, 2009, 21(3) : 335-344.]

[41] Martens CS, Klump JV. Biogeochemical cycling in an organic-rich coastal marine basin - I . Methane sediment-water exchange processes. Geochimica et Cosmochimica Acta, 1980, 44(3) : 471-490. DOI: 10.1016/0016-7037(80) 90045-9. 